\title{
Level, pattern, and determinants of polypharmacy and inappropriate use of medications by village doctors in a rural area of Bangladesh
}

This article was published in the following Dove Press journal:

ClinicoEconomics and Outcomes Research

3 December 2014

Number of times this article has been viewed

\section{Rafia S Rasu' \\ Mohammad lqbal ${ }^{2}$ \\ SMA Hanifi² \\ Ariful Moula ${ }^{2}$ \\ Shahidul Hoque ${ }^{2}$ \\ Sabrina Rasheed ${ }^{2}$ \\ Abbas Bhuiya ${ }^{2}$}

'School of Pharmacy, University of Missouri-Kansas City, Kansas City, MO, USA; ${ }^{2}$ Centre for Equity and Health System, International Centre for Diarrhoeal Disease Research (ICDDR,B), Dhaka, Bangladesh

Video abstract

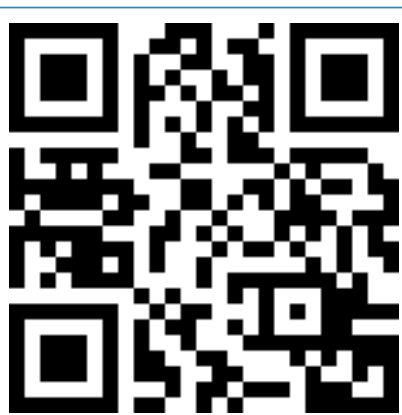

Point your SmartPhone at the code above. If you have a QR code reader the video abstract will appear. Or use: http://dvpres//td9A2Q

Correspondence: Rafia S Rasu School of Pharmacy, Doctoral Faculty of Henry W Bloch School of Management, University of MissouriKansas City, 2464 Charlotte Street,

Kansas City, MO, USA

Tel + I 8162355498

Email rafiarasu@gmail.com
Objective: Village doctors, informal health care providers practicing modern medicine, are dominant health care providers in rural Bangladesh. Given their role, it is important to examine their prescription pattern and inappropriate use of medication.

Methods: These cross-sectional study data were collected through surveys of patients seen by village doctors during 2008 and 2010 at Chakaria, a typical rural area of Bangladesh. Categorization of appropriate, inappropriate, and harmful prescriptions by disease conditions was based on guidelines defined by the World Health Organization (WHO), the United Nations Children's Fund (UNICEF), and the Government of Bangladesh. Analytical categorization of polypharmacy was defined when five or more medications were prescribed for a patient at a single visit.

Findings: A total of 2,587 prescriptions were written by village doctors during the survey periods. Among the prescriptions were appropriate (10\%), inappropriate $(8 \%)$, combination of appropriate and inappropriate (63\%), and harmful medications (19\%). Village doctors with more than high school education were 53\% less likely (odds ratio [OR]: $0.47,95 \%$ confidence interval [CI]: $0.26-0.86$ ) to give polypharmacy prescriptions than those with less than high school education. While exploring determinants of prescribing inappropriate and harmful medications, this study found that polypharmacy prescriptions were six times more likely [OR: $6.00,95 \% \mathrm{CI}$ : 3.88-9.29] to have harmful medications than prescriptions with $<5$ medications.

Conclusion: Village doctors' training and supervision may improve the quality of services and establish accountability for the benefit of the rural population.

Keywords: Bangladesh, harmful medication, ICDDR,B, informal health care providers, polypharmacy, rural area, village doctors

\section{Introduction}

Village doctors, ${ }^{1,2}$ a group of informal health care providers practicing modern medicine, are a dominant (over $80 \%$ of the providers) group of health care providers in Bangladesh, especially in rural areas. ${ }^{2-6}$ The majority of village doctors do not have any formal professional training to provide modern health care services. ${ }^{1}$ Although the health sector in Bangladesh has experienced policy formulations and health care reforms in the last 40 years, ${ }^{4}$ many rural people are still deprived of care provided by professionally trained health care providers. While the government has taken steps to acknowledge the need of rural people to provide basic modern health care to $a l l,{ }^{3}$ poor transportation infrastructure and lack of access to formally trained health care providers makes health care unreachable for many rural people. Therefore, these informal health care providers have become the sole provider for poor and underserved people in rural areas due to their easy access and consistent health services at times of need. ${ }^{2-8}$ It has 
been reported that "Close proximity of clients, availability to the community through day and night, sympathetic behavior, strong established relationship within the community, and flexible payment methods ${ }^{{ }^{3,7-9}}$ are common reasons for rural people to seek care from village doctors. In some other countries, such as the People's Republic of China, village doctors get remuneration from the government for providing public health services in rural areas. ${ }^{1}$ Moreover, village doctors in China are recognized in China's health care markets and are being integrated into rural China's surveillance system. ${ }^{1,10-12}$ No such system exists for village doctors in Bangladesh although they represent $80 \%$ of health care providers in rural Bangladesh., ${ }^{3,5,7}$

Acknowledging the need for improved health in the poor and underserved rural population, the establishment of an accountable health system at the local level is needed to enhance health care accessibility for all. ${ }^{1,3,6}$ This informal health care sector is largely unregulated and not supervised in Bangladesh; therefore, exploration of village doctors' prescription practice patterns is warranted to identify their ability to consistently provide adequate medical services to the poor and underserved rural population. Village doctors' inappropriate prescribing and overprescribing of medications, ${ }^{3,7-9}$ has been reported in previous studies, especially when medications were prescribed and dispensed by medical assistants/ paramedics. ${ }^{13}$ Prevalent cultural pressure from patients to prescribe something (at least one medication) during a visit can lead to polypharmacy, meaning prescribing five or more medications in a visit for a patient. ${ }^{14-19,13}$ Therefore, it is important to investigate polypharmacy prevalence among village doctors in Bangladesh. The International Centre for Diarrhoeal Disease Research, Bangladesh (ICDDR,B) embarked on a study to understand the nature of health care services provided by village doctors. This study reports findings on the extent of use of polypharmacy ( $\geq 5$ medications), use of inappropriate drugs, and their determinants in rural areas of Bangladesh.

\section{Materials and methods Methods}

The study utilized data from a research protocol that was approved by the ICDDR,B Ethical Review Committee, which is an internationally recognized ethics review committee. Data for this study were collected from patient prescriptions $(\mathrm{N}=2,587)$ written by village doctors during 2008 and 2010 at Chakaria, a typical rural area in Bangladesh. The survey involved collection of data on patients' symptoms of sickness, listing of medication prescribed, and village doctors' (prescribers') demographic information and education status. The unit of analysis was prescriptions written by the village doctors.

\section{Data collection}

Data were collected by a survey questionnaire used by a group of trained field workers. Informed consent was obtained from both the patients and the village doctors before starting data collection. Patients' information and prescriptions written by the village doctors during those visits were collected by sixteen trained data collectors and researchers. Village doctors and patients' participation were voluntary. Each diagnosis made and if medication was prescribed by the village doctors were noted for this study. Patients were approached by the study investigators/data collectors for their participation in this study right after they left the chamber/pharmacy (where village doctors see patients). A quality check was conducted by expert researchers during several stages of the study period. For example, to reduce data collector error, data collection was verified for reliability and consistency. Analytical variables were created for data analyses. Data analysis and interpretation were carried out in two phases by two data analysts for accuracy and reliability.

\section{Creation of analytical variables}

Categorization of appropriate, inappropriate, and harmful prescriptions by disease condition was created based on guidelines defined by the World Health Organization (WHO), the United Nations Children's Fund (UNICEF), and the Government of Bangladesh. ${ }^{3,20}$ These guidelines were arranged and categorized by professionally trained physicians with extensive experience in clinical practices and public health research. For example, the appropriate medications category for pneumonia includes antibiotics (erythromycin, azithromycin, amoxicillin, co-trimoxazole, and penicillin), use of oxygen, saline nasal drops, and acetaminophen. Inappropriate and harmful medications categories for pneumonia include dexamethasone, nonsteroidal anti-inflammatory drugs (NSAIDs), prednisolone, and pseudoephedrine. For common cold and viral fever diagnoses, the appropriate medications category includes acetaminophen. Antibiotics were considered inappropriate if prescribed for common cold and viral fever diagnoses. In addition, NSAIDs, aspirin, and steroids were considered to be in the harmful medication category if prescribed for common cold and viral fever diagnoses. Regarding diarrhea diagnosis, the appropriate medications category included oral rehydration solution (ORS), intravenous cholera saline, and zinc sulfate. Steroids and loperamide 
were considered to be harmful prescriptions if they were prescribed for diarrhea diagnosis. ${ }^{3,20}$ Previous reports showed that village doctors in Bangladesh prescribe steroids, ${ }^{3,6}$ which are considered harmful for the patient. Therefore, for the purposes of this study, it was important to define the harmful medications category separately in addition to inappropriate medications categorization. The main analytical variables for this study were categorized based on WHO, UNICEF, and the Government of Bangladesh treatment guidelines. ${ }^{3,20}$

Analytical categorization of polypharmacy was made when five or more medications were prescribed for a patient at a single visit. By searching the literature on the subject, we found that polypharmacy is defined as prescribing five or more medications during a single visit for a patient. ${ }^{14-19}$ Polypharmacy was a vital component to be looked at as evidence showed that treating patients with multiple medications, ie, polypharmacy, can adversely affect patient outcomes. ${ }^{14-16,19,21-23}$

\section{Data analysis}

Descriptive statistics for all study variables were evaluated. The main analytical variables created for the purpose of this study (appropriate, inappropriate, and harmful prescriptions, and polypharmacy status) were assessed for reporting. Multilevel generalized logistical regression analyses were carried out to assess the determinants of polypharmacy status and use of inappropriate medications by village doctors. Data were analyzed by using STATA ${ }^{\circledR}$ software (StataCorp LP, College Station, TX, USA).

\section{Study area}

The study was carried out in Chakaria, Bangladesh, which is located in the south-eastern part of the country near the coast of the Bay of Bengal. Chakaria is one of the low-performing areas of the country, with relatively high mortality and high fertility and low level of utilization of health care services. The health care delivery system in the study area comprises public, private, and nongovernmental organizations (NGOs). At present, the Upazila Health Complex of the government and four private hospitals provide health care services at the headquarters of Chakaria. At the union level, 14 community clinics, seven Union Health and Family Welfare Centres (UHFWCs), and one rural dispensary (RD) of the government provide health care services in the Chakaria Health and Demographic Surveillance System area. About eleven midwives have been providing safe motherhood services (antenatal care, postnatal care, and delivery services) in seven village health posts that were established by community members with technical assistance from ICDDR,B.
The Family Development Services and Research (FDSR), an NGO, also provides health care services in this area. Apart from these, the health care services of 242 village doctors (allopathic and homeopathic) dominate the health service delivery in this area.

\section{Results}

A total of 2,587 prescriptions were collected during the study period. Among these prescriptions, 254 (9.82\%) had appropriate medications, $219(8.47 \%)$ had inappropriate medications, 479 (18.52\%) had harmful medications, and 1,635 (63.20\%) had both appropriate and inappropriate medications prescribed by village doctors. Figure 1 shows the prescription appropriateness distribution of the total prescriptions ( $10 \%$ were appropriate, $8 \%$ inappropriate, $63 \%$ a combination of appropriate and inappropriate drugs, and 19\% harmful). Polypharmacy was found in 138 (5.33\%) prescriptions. There was no case in which patients were not given a prescription medication (Table 1). The common cold diagnosis was the most prevalent $(67.22 \%, \mathrm{n}=1,739)$ disease state in this study population, followed by pneumonia for children under 5 years old $(16.74 \%, \mathrm{n}=433)$, and diarrhea $(16.04 \%$, $\mathrm{n}=415$ ). All prescriptions included in this study were written by 77 informal health care providers (village doctors). The mean number of medications per prescription was 3 (standard deviation [SD]: 1.04, range 1-9).

The village doctors' average age was 37 years (SD: 11 years; range $18-61$ years). Their average years in practice were 13 years (SD: 9 years). On average, they had 12 years of secular education, which varied from 9 years to 16 years. Table 2 shows the prescription variation seen by prescribers' characteristics.

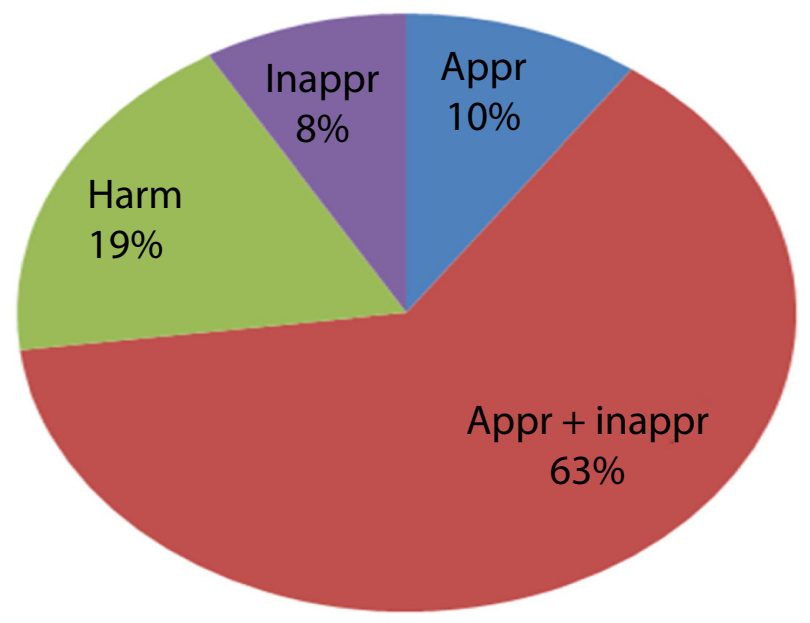

Figure I Categories of prescriptions based on appropriateness. Abbreviations: appr, appropriate; harm, harmful; inappr, inappropriate. 
Table I Prescription categories (inappropriate, harmful, and appropriate and inappropriate) by number of medications prescribed

\begin{tabular}{|c|c|c|}
\hline $\begin{array}{l}\text { Prescription } \\
\text { category }\end{array}$ & $\begin{array}{l}\text { Number of medications } \\
\text { prescribed }\end{array}$ & Percentage \\
\hline \multicolumn{3}{|l|}{ prescriptions } \\
\hline I & 67 & $26.38 \%$ \\
\hline 2 & 181 & $51.57 \%$ \\
\hline 3 & 54 & $21.26 \%$ \\
\hline 4 & I & $0.39 \%$ \\
\hline 5 & 0 & $0 \%$ \\
\hline$>5$ & I & $0.39 \%$ \\
\hline Inappropriate & 219 & \\
\hline \multicolumn{3}{|l|}{ prescriptions } \\
\hline 1 & 100 & $45.66 \%$ \\
\hline 2 & 85 & $38.81 \%$ \\
\hline 3 & 28 & $12.79 \%$ \\
\hline 4 & 6 & $2.74 \%$ \\
\hline 5 & 0 & $0 \%$ \\
\hline$>5$ & 0 & $0 \%$ \\
\hline \multicolumn{3}{|l|}{ prescriptions } \\
\hline I & 18 & $3.76 \%$ \\
\hline 2 & 29 & $6.05 \%$ \\
\hline 3 & 177 & $36.95 \%$ \\
\hline 4 & 184 & $38.41 \%$ \\
\hline 5 & 45 & $9.39 \%$ \\
\hline$>5$ & 26 & $5.43 \%$ \\
\hline $\begin{array}{l}\text { Appropriate } \\
\text { and inappropriate } \\
\text { prescriptions }\end{array}$ & 1,635 & \\
\hline 1 & 0 & $0 \%$ \\
\hline 2 & 521 & $31.87 \%$ \\
\hline 3 & 814 & $49.79 \%$ \\
\hline 4 & 234 & $14.31 \%$ \\
\hline 5 & 49 & $3 \%$ \\
\hline$>5$ & 17 & $1.04 \%$ \\
\hline
\end{tabular}

Statistically significant determinants of polypharmacy (Table 3) were the prescriber's education level and their age. Village doctors with more than high school education were $53 \%$ less likely (odds ratio [OR]: $0.47,95 \%$ confidence interval [CI]: $0.26-0.86$ ) to give polypharmacy prescriptions than those with less than high school education.

While exploring determinants of prescribing inappropriate and harmful medications (Table 4), we found that polypharmacy prescriptions were six times more likely (OR: 6.00, 95\% CI: 3.88-9.29) to have harmful medications than prescriptions with $<5$ medications. Patients with diarrhea were $86 \%$ less likely (OR: $0.14,95 \%$ CI: $0.08-0.24)$ to have harmful medications than patients with the common cold.

\section{Discussion}

Village doctors are important stakeholders in the rural health system in Bangladesh. They cater to a large sector of the population and address a wide spectrum of health conditions. ${ }^{2,3,6}$ It is suggested that effective interventions that can potentially augment the abilities of the village doctors as health care service providers are a better option rather than waiting for revamping of the overall health care system. ${ }^{2,3,6}$ This would be particularly true for a rural area of Bangladesh where the poor and underserved people need treatment and professionally trained health care providers are absent. The intervention created by ICDDR,B for the village doctors showed a modest but promising impact, particularly in reducing polypharmacy prevalence - specifically, reducing harmful prescribing that can be replicated at a larger scale to address this issue in rural Bangladesh.

Table 2 Prescription variation by prescribers' characteristics

\begin{tabular}{|c|c|c|c|c|c|c|}
\hline \multirow[t]{2}{*}{ Variables } & \multirow{2}{*}{$\begin{array}{l}\text { Total } \\
\text { prescriptions }\end{array}$} & \multicolumn{5}{|c|}{ Prescriptions (\%) } \\
\hline & & Appropriate & Inappropriate & $\begin{array}{l}\text { Appropriate and } \\
\text { inappropriate }\end{array}$ & Harmful & Total \\
\hline \multicolumn{7}{|l|}{ Prescriber's age categories } \\
\hline $18-30$ years & 900 & 9.67 & 8.78 & 69.67 & 19.89 & 100 \\
\hline $31-40$ years & 895 & 11.40 & 9.05 & 61.79 & 17.77 & 100 \\
\hline$>40$ years & 792 & 8.21 & 7.45 & 66.54 & 17.80 & 100 \\
\hline \multicolumn{7}{|l|}{ Prescriber's occupation } \\
\hline Village doctors & 2,531 & 9.88 & 8.49 & 62.86 & 18.77 & 100 \\
\hline Paramedics & 56 & 7.14 & 7.14 & 78.57 & 7.14 & 100 \\
\hline \multirow{2}{*}{\multicolumn{7}{|c|}{$\begin{array}{l}\text { Prescriber's academic } \\
\text { education level }\end{array}$}} \\
\hline & & & & & & \\
\hline Less than high school & 551 & 8.71 & 9.44 & 68.60 & 13.25 & 100 \\
\hline High school & I,407 & 10.66 & 8.60 & 60.77 & 19.97 & 100 \\
\hline More than high school & 629 & 8.9 & 7.31 & 63.91 & 19.87 & 100 \\
\hline Practiced for $\leq 10$ years & 1,223 & 11.28 & 7.93 & 62.83 & 19.72 & 100 \\
\hline
\end{tabular}

Notes: Total number of prescribers surveyed $=77$. All of them were male. The total number of prescriptions written by them was 2,587 (N). 
Table 3 Determinants of polypharmacy prescribed by village doctors

\begin{tabular}{|c|c|}
\hline Variables & $\begin{array}{l}\text { Polypharmacy: } \\
\text { OR }(95 \% \mathrm{CI})\end{array}$ \\
\hline \multicolumn{2}{|l|}{ Disease state } \\
\hline Common cold & I.0 (reference group) \\
\hline Pneumonia for children $<5$ years old & $0.77(0.46-1.29)$ \\
\hline Diarrhea & $\mathrm{I} .45(0.92-2.29)$ \\
\hline \multicolumn{2}{|l|}{ Education level } \\
\hline Less than high school & I.0 (reference group) \\
\hline High school & $0.96(0.0 .57-1.62)$ \\
\hline More than high school & $0.47(0.26-0.86)$ \\
\hline \multicolumn{2}{|l|}{ Prescriber's age } \\
\hline $18-30$ years & 1.0 (reference group) \\
\hline $31-40$ years & $3.03(1.75-5.25)$ \\
\hline$>40$ years & $1.81(0.92-3.57)$ \\
\hline Practiced for $\leq 10$ years & $0.83(0.52-1.32)$ \\
\hline
\end{tabular}

Note: Statistically significant $P$-values are bolded.

Abbreviations: $\mathrm{Cl}$, confidence interval; $\mathrm{OR}$, odds ratio.

The village doctors' prescribing trend showed that none of the visits resulted in zero prescriptions. A similar prescribing trend (no medication prescribed during a visit) was noted among professionally trained formal health care providers in Dhaka metropolitan city. ${ }^{24}$ Based on anecdotal data and our study finding, ${ }^{25}$ we think that this is a result of a cultural phenomenon associated with patient and physician behavior. Further investigation is indicated, which may open up scope for further education to improve the quality of care.

Previous studies reporting audits of prescriptions in primary care hospitals indicated a high rate of harmful injection usage (not indicated by disease diagnosis), medical inappropriateness, and unsafe use of injections in Bangladesh. ${ }^{13,25}$ We found that there is a greater likelihood (OR: 6, 95\% CI: 3.88-9.29) of prescribing harmful medications among polypharmacy prescribers as compared to those who prescribed fewer medications. Overall, rates of polypharmacy $(5.33 \%)$ and harmful medication use $(15 \%)$ were very similar to other studies reporting common prevalence of polypharmacy and deviation from appropriate prescribing in Bangladesh. ${ }^{24,26}$ The broader question is really to what extent prescribing $>5$ medications is considered inappropriate for the listed conditions. This would require a more expansive understanding of the current best practice guidelines. Cultural pressure to prescribe something (at least one medication) during a visit and unnecessary prescribing may lead to polypharmacy and harmful medication. Whether this complex situation is due to cultural influence or a true prevalence of multiple comorbidities among patients driving the trend of polypharmacy and harmful prescribing is a query that needs further investigation.

Although direct consumer advertising for pharmaceutical products is not legal in Bangladesh, "patient's demand" was observed to be one of the many reasons behind the popularity of injections in Bangladesh. ${ }^{13}$ "A tendency to overprescribe injections" was reported when medications were prescribed and dispensed by medical assistants/paramedics. ${ }^{13}$ Lack of knowhow about disease management and easily accessible medications might be the explanation of such prescribing behavior.

These findings warrant effective and rigorous training and an awareness program to impact the culture of overprescribing among village doctors. The major challenge in

Table 4 Determinants of prescribing inappropriate and harmful medications by village doctors

\begin{tabular}{|c|c|c|c|c|}
\hline Variables & $\begin{array}{l}\text { Appropriate use: } \\
\text { OR }(95 \% \mathrm{CI})\end{array}$ & $\begin{array}{l}\text { Inappropriate use: } \\
\text { OR }(95 \% \mathrm{CI})\end{array}$ & $\begin{array}{l}\text { Harmful use: } \\
\text { OR (95\% CI) }\end{array}$ & $\begin{array}{l}\text { Appropriate and } \\
\text { inappropriate use: } \\
\text { OR }(95 \% \mathrm{CI})\end{array}$ \\
\hline$>5$ medications prescribed & $0.08(0.01-0.58)$ & Omitted & $6.00(3.88-9.29)$ & $0.52(0.35-0.76)$ \\
\hline \multicolumn{5}{|l|}{ Disease state } \\
\hline Common cold & I.0 (reference group) & I.0 (reference group) & I.0 (reference group) & I.0 (reference group) \\
\hline Pneumonia for children $<5$ years old & $3.49(2.6 I-4.68)$ & $\mathrm{I} .06(0.70-\mathrm{I} .60)$ & $\mathrm{I} .02(0.76-\mathrm{I} .35)$ & $0.50(0.40-0.63)$ \\
\hline Diarrhea & $0.23(0.05-0.31)$ & $2.84(2.05-3.93)$ & $0.14(0.08-0.24)$ & $1.95(1.50-2.54)$ \\
\hline \multicolumn{5}{|l|}{ Education level } \\
\hline Less than high school & I.0 (reference group) & I.0 (reference group) & I.0 (reference group) & 1.0 (reference group) \\
\hline High school & $1.06(0.66-1.69)$ & $0.99(0.63-1.55)$ & $1.19(0.63-2.23)$ & $0.79(0.53-1.18)$ \\
\hline More than high school & $0.98(0.58-1.67)$ & $0.8 \mathrm{I}(0.49-\mathrm{I} .33)$ & $1.50(0.76-2.98)$ & $0.77(0.50-\mathrm{I} .20)$ \\
\hline \multicolumn{5}{|l|}{ Prescriber's age } \\
\hline $18-30$ years & I.0 (reference group) & I.0 (reference group) & I.0 (reference group) & I.0 (reference group) \\
\hline $31-40$ years & $1.48(0.92-2.36)$ & $0.99(0.64-1.54)$ & $0.45(0.22-0.91)$ & $\mathrm{I} .33(0.87-2.05)$ \\
\hline$>40$ years & $0.98(0.66-1.69)$ & $0.66(0.39-I . I I)$ & $0.64(0.29-I .4 I)$ & $\mathrm{I} .57(0.95-2.59)$ \\
\hline Practiced for $\leq 10$ years & $1.10(0.68-1.78)$ & $0.68(0.44-1.04)$ & $0.8 \mid(0.44-\mid .57)$ & I.35 (0.89-2.04) \\
\hline
\end{tabular}

Notes: $\mathrm{N}=2,587$, using the generalized linear multilevel model; statistically significant $P$-values are bolded.

Abbreviations: $\mathrm{Cl}$, confidence interval; $\mathrm{OR}$, odds ratio. 
this context could be the financial incentive associated with prescribing more medications by village doctors who make their living from the profit they make by selling medications. Added to the complexity in this context is the aggressive marketing of medications by pharmaceutical companies, which at times incentivize the selling of medications by their sales agents, including village doctors. Regardless of their inappropriate prescribing and overprescribing of medications, ${ }^{3,7-9}$ village doctors need to be incorporated within the health care system with necessary training to avoid harmful practices and promote safe and quality care for the rural population of Bangladesh. Innovation and effective training are needed to improve the quality of services and establish accountability for the benefit of the rural population in general and the poor in particular. Use of modern technology (eg, mobile phones) with a centralized system may help these informal health care providers to seek advice from professionally trained health care providers at times of need, which may ultimately alleviate demands on the health care system (access, safety, quality, cost, and provider shortages) and improve outcomes. Remunerating village doctors for public health services and the supervising of village doctors by local government county health bureaus such as those in the People's Republic of China, are being instituted. ${ }^{1,10-12}$ Although limited supervision and inadequate remuneration have been reported by village doctors in the People's Republic of China, implementation of the efficient "Integrated Surveillance System in Rural China" project aims to improve detection of epidemics in rural People's Republic of China. Such systems may improve the rural health care situation for village doctors in Bangladesh where there is a broader need for an efficient epidemic surveillance system for rural Bangladesh.

\section{Limitations}

Patient demographic information was not available, which would have strengthened this study. However, this study included patient diagnoses or reasons for visits to village doctors to define appropriate, inappropriate, and harmful treatments. Patients seen by these village doctors were not followed over time continually to evaluate their treatment outcome. Lastly, this study cannot ascertain if these prescriptions were ultimately filled by these patients or not. We only know what was prescribed during that visit.

\section{Conclusion}

It is important to address the quality of prescriptions written by village doctors in rural Bangladesh. Training and supervision are needed to improve the quality of services and to establish accountability for the benefit of the rural population in general and particularly among the poor. Given the importance of village doctors in health care and their use of modern medicine in the face of a huge shortage of formally trained providers, it is important that due attention and training is given to them.

\section{Acknowledgments}

The study was funded by the Swedish International Development Cooperation agency (SIDA), grant number 00599; Rockefeller Foundation, grant number 00658; and the Department for International Development (DFID), grant number 00445. ICDDR,B acknowledges with gratitude the commitment of SIDA, Rockefeller Foundation, and DFID to its research efforts. Part of this analysis and manuscript generation was supported by the School of Pharmacy of the University of Missouri-Kansas City, MO, USA.

The authors would like to thank Dr Maureen Knell, Clinical Associate Professor of Pharmacy Practice and Administration, for providing editorial suggestions in the final version of the manuscript.

\section{Disclosure}

The authors report no conflicts of interest in this work.

\section{References}

1. Ding Y, Smith HJ, Fei Y, et al. Factors influencing the provision of public health services by village doctors in Hubei and Jiangxi provinces, China. Bull World Health Organ. 2013;91(1):64-69.

2. Mahmood SS, Iqbal M, Hanifi SM, Wahed T, Bhuiya A. Are 'Village Doctors' in Bangladesh a curse or a blessing? BMC Int Health Hum Rights. 2010;10:18

3. Wahed T, Rasheed S, Bhuiya A, editors. Doctoring the Village Doctors: Giving Attention Where it is Due. Dhaka, Bangladesh: ICDDR,B; 2012.

4. Bangladesh Health Watch. Moving Towards Universal Health Coverage. Dhaka, Bangladesh: Bangladesh Health Watch; 2012.

5. Bangladesh Health Watch. Health Workforce in Bangladesh: Who Constitutes the Healthcare System? Dhaka, Bangladesh: Bangladesh Health Watch; 2008.

6. Bhuiya A, editor. Health for the Rural Masses: Insights from Chakaria. Dhaka, Bangladesh: ICDDR,B; 2009.

7. Wahed T, Alamgir F, Urni F, Bhuiya A. Engaging with village doctors to improve quality of healthcare in Chakaria. Future Health Systems Research Brief. 2009;4:1-4.

8. Bloom G, Champion C, Lucas H, Peters D, Standing H. Making health markets work better for poor people: Improving provider performance. Future Health Systems Research Brief. 2009;6:1-5.

9. Wahed T. Costs of utilizing healthcare services in Chakaria, a rural area in Bangladesh. Future Health Systems Research Brief. 2009;2:1-4.

10. Bloom G, Kanjilal B, Peters DH. Regulating health care markets in China and India. Health Affairs. 2008;27(4):952-963.

11. Liu Y, Hsiao WC, Li Q, Liu X, Ren M. Transformation of China's rural health care financing. Soc Sci Med. 1995;41(8):1085-1093.

12. Suggestions on further enhancing the construction of village doctors. SCPRC; 2011. Available from: http://www.gov.cn/zwgk/2011-07/14/ content_1906244.htm. Accessed October 3, 2012. Chinese. 
13. Chowdhury A, Roy T, Faroque A, et al. A comprehensive situation assessment of injection practices in primary health care hospitals in Bangladesh. BMC Public Health. 2011;11:779.

14. Rasu RS, Sohraby R, Cunningham L, Knell ME. Assessing chronic pain treatment practices and evaluating adherence to chronic pain clinical guidelines in outpatient practices in the United States. J Pain. 2013;14(6):568-578.

15. Rasu RS, Jayawant SS, Abercrombie M, Balkrishnan R. Treatment of anemia among women with chronic kidney disease in United States outpatient settings. Womens Health Issues. 2009;19(3):211-219.

16. Polypharmacy. Family Practice Notebook; 2013. Available from: http://www.fpnotebook.com/geri/Pharm/Plyphrmcy.htm. Accessed August 16, 2013.

17. Agbor Bawa W, Rianon N, Lafferty W, Rasu R. Polypharmacy and its impact on healthcare utilization: Evidence from national data 2005-2008. In: Academy of Managed Care Pharmacy (AMCP) annual meeting; April 3-5, 2013; San Diego, CA.

18. Agbor Bawa W, Rianon N, Rasu R. Polypharmacy and self-perceived health status in older patients. In: International Society of Pharmacoeconomics and Outcomes Research (ISPOR) 18th Annual International Meeting; May 18-22, 2013; New Orleans, LA.

19. Rasu R, Abercrombie M. Polypharmacy trend in women with chronic kidney disease in US outpatient settings. In: ISPOR 13th Annual International Meeting; May 3-7, 2008; Toronto, Ontario.
20. Government of Bangladesh, WHO. Integrated management of childhood illness (IMCI). Dhaka, Bangladesh; 2003.

21. Rasu RS, Crawford T, Manley H, Balkrishnan R. Treatment and costs associated with anemic chronic kidney disease patients. Curr Med Res Opin. 2008;24(1):129-137.

22. Leendertse AJ, Egberts AC, Stoker LJ, van den Bemt PM; HARM Study Group. Frequency of and risk factors for preventable medicationrelated hospital admissions in The Netherlands. Arch Intern Med. 2008;168(17):1890-1896.

23. Linton A, Garber M, Fagan NK, Peterson MR. Examination of multiple medication use among TRICARE beneficiaries aged 65 years and older. J Manag Care Pharm. 2007;13(2):155-162.

24. Alam M, Parveen F, Ara F, Iqbal M, Saha R. Prescribing trends in the out patient department in a tertiary hospital in Bangladesh. Bangladesh Med J. 2011;40(2):8-12.

25. Chowdhury A, Rahman S, Faroque A, Hasan G, Zahir Raihan S. Wide spread injection use in the hospitals of the upazila health complexes of Bangladesh. Mymensingh Med J. 2007:123-131.

26. Paul P, Pal D, Rahman M, Islam M, Siddique A. Evaluation of prescribing practices in the outpatient departments of a teaching hospital Bangladesh Med J. 2011;40(2):19-22.

27. Hanifi MA, Mamun AA, Paul A, et al. Profile: the Chakaria Health and Demographic Surveillance System. Int J Epidemiol. 2012;41(3):667-675.
ClinicoEconomics and Outcomes Research

\section{Publish your work in this journal}

ClinicoEconomics \& Outcomes Research is an international, peerreviewed open-access journal focusing on Health Technology Assessment, Pharmacoeconomics and Outcomes Research in the areas of diagnosis, medical devices, and clinical, surgical and pharmacological intervention. The economic impact of health policy and health systems

\section{Dovepress}

organization also constitute important areas of coverage. The manuscript management system is completely online and includes a very quick and fair peer-review system, which is all easy to use. Visit http://www.dovepress.com/testimonials.php to read real quotes from published authors. 